\title{
Krajšavni slovarji
}

\author{
Mojca Kompara
}

V prispevku je predstavljen pregled zastopanosti krajšav v splošnih, specializiranih, eno- in dvojezičnih slovarjih. Posebna pozornost je namenjena tujim krajšavnim slovarjem, tako na makro- kot mikrostrukturni ravni, pri čemer so prikazane prednosti in pomanjkljivosti slovarskih rešitev. Prispevek se osredinja tudi na ustrezne slovarske vire, opiše in primerja gesla krajšavnih slovarjev ter opozori na potrebo po izgradnji slovenskega krajšavnega slovarja ter oriše smernice za nadgradnjo Slovarčka krajšav (Kompara 2006).

Ključne besede: krajšavni slovarji, makrostruktura, mikrostruktura

\section{Dictionaries of abbreviations}

This article outlines the presence of abbreviations in general, specialized, monolingual, and bilingual dictionaries. Special emphasis is given to the macro- and microstructure of non-Slovenian dictionaries of abbreviation and the various solutions applied. Available sources for the users are described, the entries in such dictionaries are compared, and the need for a contemporary Slovenian dictionary of abbreviations is explained. The article concludes with guidelines for future development of the online dictionary Slovarček krajšav (Dictionary of Abbreviations).

Key words: dictionaries of abbreviation, macrostructure, microstructure

\section{Uvod}

Krajšave so vsesplošno prisotni rastoči pojav, s katerim se v slovenskem prostoru ukvarjajo predvsem pravopisi (Kompara 2009: 96). V nadaljevanju me je zanimalo, kako so krajšave obravnavane v specializiranih krajšavnih slovarjih, predvsem na ravni mikro- in markostrukture in koliko je krajšavnih slovarjev v danem jeziku. V prispevku želim opozoriti na pomembnost izgradnje slovarja krajšav za slovenski jezik, saj krajšave zasledimo prav povsod: v dnevnem časopisju, na televiziji, radiu itn. Krajšave in krajšavne razvezave največkrat iščemo v različnih slovarjih, lahko pa posežemo tudi po drugih virih. Poraja se torej vprašanje, kje in kako lahko najdemo krajšavo in krajšavno razvezavo. Dušan Gabrovšek pravi, da so s krajšavami »križi in težave« (1994: 164). Menim, da je krajšav izredno veliko, težko pa 
- opredelimo, kdo jih res potrebuje. Zelo pomembno je, da so slovarji krajšav čim aktualnejši, ko jih kupujemo, saj se $v$ jezikih nove krajšave pojavljajo izredno hitro (Kompara 2005: 10-12).

\section{$1 \quad$ Nekaj besed o krajšavah v splošnih slovarjih}

V splošnih enojezičnih slovarjih najdemo krajšave pogosto v vlogi samostojnega gesla, tako v angleškem Collins COBUILD English Dictionary (Sinclair 1999), nemškem Deutsches Universalwörterbuch (DUW), francoskem Le Nouveau Petit Robert (Robert 1996) ali v bolj ali manj obsežnih dodatkih na začetku ali koncu slovarja, kot je značilno za italijanski slovar Zingarelli (Zingarelli 2000). Španski Clave: Diccionario de Uso del Español (García Marquez 2002) pa krajšave vključuje $\mathrm{v}$ dodatek in med gesla. $\mathrm{V}$ dvojezičnem slovarskem prostoru krajšav ne vsebujejo predvsem slovarji za enkodiranje, z izjemo predvsem novejših slovarjev, kot sta Veliki slovensko-italijanski slovar (Šlenc 2006) in Veliki slovensko-nemški slovar (Debenjak 2003). Krajšave so pogostejše v slovarjih za dekodiranje; najobsežneje so vključene v Veliki angleško-slovenski slovar Oxford-DZS, ki je izšel v letih 2005-2006.

\section{Krajšave v krajšavnih slovarjih}

V nadaljevanju se osredinjam na makro- in mikrostrukturo krajšavnih slovarjev in v ta namen opazujem geselske članke tujejezičnih slovarjev krajšav. V prispevku primerjam različne angleške slovarje krajšav, dva nemška ter dva italijanska, francoskega in španskega in povzamem poglavitne značilnosti ter primerjam prednosti in pomanjkljivosti.

\subsection{Angleški krajšavni slovarji}

$\mathrm{V}$ angleškem prostoru sem opazovala tele slovarje krajšav: Dictionary of $A b$ breviations (Paxton 1983), The New Penguin Dictionary of Abbreviations (Fergusson 2000), Abbreviations Dictionary (De Sola 1986), World Guide to Abbreviations of Organizations (Buttress 1976), Dictionary of Abbreviations and Acronyms (Dale 1999), Abbreviations and Acronyms (Geddes - Grosset 1999), Acronyms, Initialisms and Abbreviations Dictionary (Gale Research Company 2006), The Barnhart Abbreviations Dictionary (Barnhart 1995), The Dictionary of Acronyms and Abbreviations in Applied Linguistics and Language Learning (Jung 1991) in Elsevier's Dictionary of Acronyms, Initialisms, Abbreviations and Symbols (Mattia 1997). Temeljne značilnosti mikrostrukture so ponazorjene $\mathrm{v}$ spodnji preglednici. 
Preglednica 1

\begin{tabular}{|l|l|l|l|l|l|l|l|}
\hline Slovar & $\begin{array}{l}\text { Število } \\
\text { gesel }\end{array}$ & $\begin{array}{l}\text { Doda- } \\
\text { tek }\end{array}$ & $\begin{array}{l}\text { Tuje } \\
\text { krajša- } \\
\text { ve }\end{array}$ & Prevod & $\begin{array}{l}\text { Kvali- } \\
\text { fikator }\end{array}$ & Jezik & $\begin{array}{l}\text { Enciklopedični } \\
\text { podatki }\end{array}$ \\
\hline Paxton 1983 & 25.000 & $\checkmark$ & $\checkmark$ & $\checkmark \checkmark$ & $\checkmark$ & $\checkmark \times$ & $\checkmark$ \\
\hline Fergusson 2000 & 40.000 & $\checkmark$ O & $\checkmark$ & $\checkmark \checkmark$ & $\checkmark$ & $\checkmark$ & $\checkmark$ R \\
\hline De Sola 1986 & 23.000 & $\checkmark$ O & $\checkmark$ & $\checkmark \checkmark$ & $x$ & $\checkmark$ & $\checkmark$ R \\
\hline Buttress 1976 & 60.000 & $x$ & $\checkmark$ & $x$ & $x$ & $x$ & $x$ \\
\hline Dale 1999 & 20.000 & $\checkmark$ PO & $\checkmark$ & $\checkmark \checkmark$ & $\checkmark$ & $\checkmark$ & $\checkmark$ \\
\hline $\begin{array}{l}\text { Geddes - Grosset } \\
\text { 1999 }\end{array}$ & 10.000 & $x$ & $\checkmark$ & $\checkmark \checkmark$ & $\checkmark$ & $\checkmark$ & $x$ \\
\hline $\begin{array}{l}\text { Gale Research } \\
\text { Company 2006 }\end{array}$ & 1.000 .000 & $x$ & $\checkmark$ & $\checkmark \checkmark$ & $\checkmark$ & $x$ & $\checkmark$ \\
\hline Barnhart 1995 & 60.000 & $x$ & $\checkmark$ & $\checkmark \checkmark$ & $\checkmark$ & $\checkmark$ & $\checkmark$ \\
\hline Jung 1991 & 50.000 & $x$ & $\checkmark$ & $x$ & $\checkmark x$ & $x$ & $x$ \\
\hline Mattia 1997 & 60.000 & $\checkmark$ & $\checkmark$ & $x$ & $x$ & $x$ & $x$ \\
\hline
\end{tabular}

Legenda

\begin{tabular}{|l|l|l|l|l|l|l|}
\hline $\boldsymbol{X}-\mathrm{ne}$ & $\checkmark-\mathrm{da}$ & $\begin{array}{l}\checkmark \checkmark-\mathrm{da} \\
(\mathrm{dos} l e d n o)\end{array}$ & $\begin{array}{l}\checkmark x-\mathrm{da} \\
(\text { ne dosledno) }\end{array}$ & $\begin{array}{l}\checkmark \mathrm{O}-\mathrm{da} \\
(\text { obsežni) }\end{array}$ & $\begin{array}{l}\checkmark \mathrm{R}-\mathrm{da} \\
(\text { redko) }\end{array}$ & $\begin{array}{l}\checkmark \mathrm{PO}-\mathrm{da} \\
(\text { preobsežno })\end{array}$ \\
\hline
\end{tabular}

Predstavljeni in analizirani angleški krajšavni slovarji se razlikujejo že po številu gesel. Razlike so očitne tudi na mikrosturkturni ravni, predvsem pri prevodih, ki v geslih žal niso dosledno beleženi ali pa jih sploh ni. Prevodi krajšav pa predstavljajo podatek, ki bi moral biti v krajšavnem slovarju dosledno naveden, saj slovar brez prevodov uporabniku vprašanja ne reši, ampak mu porodi novo. Iz preglednice je razvidno tudi, da nekateri slovarji nimajo dodatkov, spet drugi pa se bohotijo $\mathrm{s}$ preobsežnimi. Tudi kvalifikatorjev, podatkov o izvornem jeziku in enciklopedičnih podatkov ni v vseh slovarjih. Bistveni del, ki bi moral biti vključen v vsako krajšavno delo, je tudi obrnjeni slovar, ki uporabnika popelje od razvezave do krajšave; tak je Reverse Acronyms Initialisms \& Abbreviations Dictionary (Gale Research Company 2007) in The Barnhart Abbreviations Dictionary (Barnhart 1995). Tak dodatek ima veliko uporabno vrednost, a ga večina slovarjev žal še nima. Ključna težava slovarjev pa je njihova starost, saj izhajajo preredko, da bi vsebovali najnovejše krajšave. - V nadaljevanju podrobneje opazujem mikrostrukturo krajšavnih slovarjev v angleškem prostoru.

\subsubsection{Everyman's Dictionary of Abbreviations}

Angleški Everyman's Dictionary of Abbreviations (Paxton 1983) vsebuje okrog 25.000 abecedno urejenih gesel in več kot 37.000 razlag ter je opremljen tudi z dodatkom. V slovarju najdemo pretežno angleške krajšave, opazimo pa lahko tudi tuje, npr. latinske, nemške ali francoske krajšave, ki so dosledno prevedene v angleški jezik, kar tudi nedvomno koristi uporabniku slovarja. Geselski članek je pre- 
- $\quad$ prost, neposredno za iztočnico, ki je zapisana krepko, najdemo s podpičjem ločene pomene krajšave, kar je razvidno iz primera 1.

Primer 1

d.c. dead centre; direct current (elec.); double column; double crochet; drift correction (nav.); It. da capo, repeat from the beginning (mus.)

Vir: Everyman's Dictionary of Abbreviations (Paxton 1983: 100)

V primeru 1 lahko vidimo rabo področnega kvalifikatorja, npr. (elec.) in (nav.), ki stoji za pomenom oz. razvezavo krajšave, jezikovni podatek pa stoji pred pomenom oz. razvezavo in je okrajšan, npr. It.; tuji pomen krajšave je zapisan ležeče, za vejico stoji prevod. Pomeni v geselskem članku so abecedno urejeni, tovrstna ureditev pa uporabniku olajša iskanje. Zanimiv je tudi primer 2.

Primer 2

DBD Demokratische Bauernpartei Deutschlands, Democratic Peasants' Party of Germany (E. Ger.)

Vir: Everyman's Dictionary of Abbreviations (Paxton 1983: 100)

V primeru 2 gre za nemško krajšavo. V geselskem članku ni podatka o jeziku, kar kaže na nedosledno rabo jezikovnega podatka $v$ geslovniku, zanimiv pa je podatek (E. Ger.), ki nakazuje območje rabe krajšave. V primeru 3 pa lahko opazimo tudi nekaj enciklopedičnosti. Za razvezavo stoji namreč še dodatni opis termina, ki uporabniku nedvomno koristi.

Primer 3

d/B decibel, unit of noise measurement

Vir: Everyman's Dictionary of Abbreviations (Paxton 1983: 100)

Če v slovarju obstajata dve ali več različic zapisa krajšave, slovar to rešuje tako, da poda oba zapisa $\mathrm{v}$ enem geselskem članku, kar je razvidno iz primera 4. Drugi zapis gesla pa v nadaljevanju slovarja ne stoji vedno kot samostojno geslo (izjema je primer 5), npr. v slovarju ni zaznati gesla dble. v vlogi samostojnega gesla.

Primer 4

dbl., dble. double

Vir: Everyman's Dictionary of Abbreviations (Paxton 1983: 100)

Zanimiv je tudi primer 5, saj nakazuje, da ni zaznati pomena krajšave day book, ki ima tudi dve različici zapisa krajšave, to sta $D / B$ in $d . b$. med pomeni enako zapisanega gesla $d . b$. , ki stoji v nadaljevanju.

Primer 5

D/B d.b. day book

d.b. double bed; double-breasted; draw bar

Vir: Everyman's Dictionary of Abbreviations (Paxton 1983: 100) 


\subsubsection{The New Penguin Dictionary of Abbreviations}

The New Penguin Dictionary of Abbreviations (Fergusson 2000) vsebuje okrog 40.000 abecedno urejenih gesel in ima na začetku slovarja obsežen dodatek, ki zajema krajšave, uporabljene v oglaševanju, spletne krajšave, tuje krajšave s področja podjetništva, krajšave za kemične elemente itn. Dodatek je zelo obširen, uporaben in posamezni sklopi v njem so abecedno urejeni. V slovarju najdemo seveda pretežno angleške krajšave, opazimo pa tudi tuje, ki so dosledno prevedene. Geslo je preprosto: neposredno za iztočnico, ki je zapisana krepko, najdemo pomene krajšave, ki so med seboj ločeni s podpičjem (primer 6).

\section{Primer 6}

CME Chicago Mercantile Exchange; Conférence mondiale de l'énergie (French: World Power Conference); [astronomy] coronal mass ejection; [USA] cost and manufacturability expert

Vir: The New Penguin Dictionary of Abbreviations (Fergusson 2000: 100)

Vidimo lahko, da so tujejezične razvezave zapisane ležeče, jezikovni podatek stoji v celoti izpisan za krajšavno tujejezično razvezavo v oklepaju, za njim pa stoji še prevod krajšave. Področni kvalifikatorji so v geselskem članku uporabljeni, npr. [astronomy]. Najdemo jih v oglatih oklepajih in v celoti izpisane. Everyman's Dictionary of Abbreviations (Paxton 1983) pa jih okrajša v okroglih oklepajih, npr. (mus.). Poleg tega lahko opazimo še podatek za območje rabe krajšave, ki tudi stoji v oglatih oklepajih npr. [USA]. Take podatke lahko najdemo tudi v slovarju Everyman's Dictionary of Abbreviations (Paxton 1983), npr. (E. Ger.). Tudi enciklopedične podatke oz. dodatno razlago je mogoče najti v geslovniku, kar je razvidno iz primera 7 . Vendar ni veliko gesel s tovrstnimi dodatki, informacije so običajno skope, npr. v primeru 8.

Primer 7

Cmd Command Paper (1919-56) (in parliamentary procedures)

Vir: The New Penguin Dictionary of Abbreviations (Fergusson 2000: 100)

Primer 8

cm. pf. cumulative preference (shares); cumulative preferred (shares)

Vir: The New Penguin Dictionary of Abbreviations (Fergusson 2000: 100)

\subsubsection{Abbreviations Dictionary}

Pregledala sem še Abbreviations Dictionary (De Sola 1986), ki šteje 23.000 abecedno urejenih gesel. Tako kot The New Penguin Dictionary of Abbreviations (Fergusson 2000) vsebuje tudi Abbreviations Dictionary obsežen dodatek. V primerjavi z njim ima Everyman's Dictionary of Abbreviations (Paxton 1983) skromnejši dodatek. V slovarju najdemo seveda pretežno angleške krajšave, so pa v njem tudi tuje, ki so dosledno prevedene. Geselski članek je preprost: uvede ga iztočnica, ki je zapisana krepko, pomeni krajšav so med seboj ločeni s podpičjem, kar je razvidno iz primera 9. 
Primer 9

aud audible; audit; audition; auditor; auditorium

Vir: Abbreviations Dictionary (De Sola 1986: 100)

V geslovniku ni podatka o področnih kvalifikatorjih, tuji jezik je izpisan v oklepaju, za tujo ležeče zapisano razvezavo, sledi pa mu prevod oz. angleška razlaga, kar je razvidno iz primera 10 , v katerem lahko opazimo tudi nekaj dodatne razlage, ki pa je v geslovniku redko uporabljena.

Primer 10

a.u.c. $a b$ urbe condita (Latin-from the founding of the city, usually refers to Rome)

Vir: Abbreviations Dictionary (De Sola 1986: 100)

\subsubsection{World Guide to Abbreviations of Organizations}

Pregledala sem še World Guide to Abbreviations of Organizations (Buttress 1976), ki vsebuje 60.000 abecedno urejenih gesel angleških in tujih organizacij. Geselski članek je preprost, neposredno za iztočnico, ki je zapisana krepko, najdemo pomene krajšav. Slabost je mogoče to, da tujejezične krajšave niso prevedene. V geselskih člankih tudi ni opaziti podatka o področnih kvalifikatorjih in jeziku, je pa navedeno, v kateri državi se krajšava uporablja, a ne vedno. Nekaj nedoslednosti je razvidnih iz primera 11.

Primer 11

CCD Conseil de Coopération Douanière (Belgium)

CCF Crédit Commercial de France

Vir: World Guide to Abbreviations of Organizations (Buttress 1976: 100)

\subsubsection{Dictionary of Abbreviations and Acronyms}

Dictionary of Abbreviations and Acronyms (Dale 1999) je še en abecedno urejen krajšavni slovar, ki vsebuje 20.000 krajšav. Slovar ima obsežen dodatek, v katerem najdemo krajšave, uporabljene v glasbi, medicini, veterini in zoologiji, geografske krajšave, meteorološke krajšave, pa tudi krajšave za kemične elemente itn. Vse krajšave v dodatku so abecedno urejene. Dodatek je zelo obširen, saj zajema kar več kot 150 strani in predstavlja več kot polovico slovarja, krajšave iz dodatka pa niso zajete v slovarskem delu. Dodatek je sicer zelo uporaben, a lahko zaradi obsega uporabnika zmede, saj ta ne ve natančno, kje iskati neko krajšavo, prej pa si mora tudi v kazalu pregledati in prebrati vsebino dodatka, kar ponovno zahteva čas za iskanje in ponoven vpogled v kazalo pri vsaki uporabi slovarja. V slovarju so pretežno angleške krajšave, najdemo pa tudi tuje, ki so dosledno prevedene. Geslo je preprosto: takoj za iztočnico, ki je zapisana krepko, najdemo pomene krajšave, ki so med seboj ločeni s podpičjem (primer 12). Zanimivo je tudi, da so v slovarju $\mathrm{v}$ en geselski članek združeni pomeni krajšav z enakim besednim korenom, kar je razvidno iz primera 12. Popolnoma ločeni, torej vsak v svojem geselskem članku, so preostali pomeni, ki pa imajo enak zapis krajšave in popolnoma drugačen pomen oz. besedni koren (primer 13). 
Primer 12

mech mechanical; mechanism; mechanic; mechanics; mechanical Vir: Dictionary of Abbreviations and Acronyms (Dale 1999: 100)

Primer 13

MC Member of Congress (USA)

MC Master Of Ceremonies

MC medium capacity (bomb) (MIL)

MC Military Cross (MIL)

MC medium coeli (Latin: mid-heaven) (SCI)

Vir: Dictionary of Abbreviations and Acronyms (Dale 1999: 100)

V primeru 13 opazimo tudi rabo področnih kvalifikatorjev, ki stojijo $\mathrm{v}$ oklepaju, ter podatek o jeziku, ki se nahaja za tujo krajšavno razvezavo in je zapisan v celoti in ležeče, sledi pa mu prevod. Če obstajata dva zapisa za krajšavo, sta oba zapisana v enem geslu. Drugi zapis ni predstavljen v samostojnem geslu, kar je razvidno iz primera 14.

\section{Primer 14}

MDS, MMDS multipoint microwave distribution system (FPA)

Vir: Dictionary of Abbreviations and Acronyms (Dale 1999: 101)

Enciklopedični podatek je mogoče najti v primeru 15; zapisan je ležeče in stoji v oklepaju za krajšavno razvezavo.

Primer 15

MF machine-finished (paper which has been surfaced while on the papermaking machine) (COM)

Vir: Dictionary of Abbreviations and Acronyms (Dale 1999: 101)

\subsubsection{Abbreviations and Acronyms}

V žepnem slovarčku Abbreviations and Acronyms (Geddes - Grosset 1999) je okrog 10.000 abecedno urejenih krajšav. Takoj za krepko zapisano iztočnico najdemo pomene krajšave, ki so med seboj ločeni s podpičjem. V slovarčku najdemo angleške in tuje krajšave, ki so dosledno prevedene (primer 16). V slovarju so tudi podatki o jeziku in področnih kvalifikatorjih. Slovarček nima dodatka.

Primer 16

BMW Bayerische Motoren Werke, German 'Bavarian Motor Works'.

Vir: Abbreviations and Acronyms (Geddes - Grosset 1999: 38)

\subsubsection{Acronyms, Initialisms and Abbreviations Dictionary} Acronyms, Initialisms and Abbreviations Dictionary (Gale Research Company 2006; na spletu je nekaj prosto dostopnih gesel: http:/www.gale.cengage.com/pdf/ samples/sp628573.pdf) je obsežen milijonski slovar, ki izide skoraj vsako leto. Slovar zajema obsežen geslovnik, vsak pomen pa nastopa v svojem geslu. Sestavljeno 
- je preprosto: uvaja ga krepko zapisana iztočnica, za katero stoji pomen (primera

[. 17 in 18), v geslu pa so lahko podatki o področnih kvalifikatorjih, enciklopedični podatki in prevodi (primer 19).

Primer 17

A-Age

Vir: Acronyms, Initialisms and Abbreviations Dictionary (Gale Research

Company 2006)

Primer 18

A - Agglomerate [Geology]

Vir: Acronyms, Initialisms and Abbreviations Dictionary (Gale Research

Company 2006)

Primer 19

AA - Andrew Public Library, Alberta [Library symbol]

[National Library of Canada] (NLC)

Vir: Acronyms, Initialisms and Abbreviations Dictionary (Gale Research

Company 2006)

Zanimiv je tudi slovar krajšavnih razvezav, ob katerih so navedene krajšave, z naslovom Reverse Acronyms Initialisms \& Abbreviations Dictionary (Gale Research Company 2007; tudi iz njega je na spletu nekaj prosto dostopnih gesel: http://www. gale.cengage.com/pdf/samples/sp628662.pdf); ta ponuja obrnjeno različico krajšavnega slovarja Acronyms, Initialisms and Abbreviations Dictionary (Gale Research Company 2006) in uporabniku omogoča, da iz razvezane oblike najde ustrezno krajšavo. Slovar izhaja redno že nekaj let kot samostojna publikacija.

\subsubsection{The Barnhart Abbreviations Dictionary}

Slovar, podoben prejšnjemu, je angleški krajšavni slovar The Barnhart Abbreviations Dictionary (Barnhart 1995), ki vsebuje več kot 60.000 krajšav. Sestavljen je iz dveh delov, slovarja krajšav in slovarja razvezav; slednji popelje bralca od krajšavne razvezave do krajšave. To je nedvomno zelo koristno delo, saj velikokrat potrebujemo tudi tovrstne podatke. Predvsem pri enkodiranju, ko iščemo zapis krajšave $\mathrm{v}$ jeziku, so taki slovarji zelo koristni. Za primerjavo bi izpostavila še francoski krajšavni slovar Dictionnaire des Abréviations Courantes de la Langue Française (Faudouas 1990), ki ponuja tudi pot od razvezave do krajšave in vsebuje na koncu še obsežen dodatek.

\subsubsection{The Dictionary of Acronyms and Abbreviations in Applied Linguistics and Language Learning}

Pot od razvezave do krajšave daje tudi The Dictionary of Acronyms and Abbreviations in Applied Linguistics and Language Learning (Jung 1991). Slednji zajema obsežen geslovnik, vsak pomen pa nastopi v samostojnem geselskem članku. Geslo uvaja krepko zapisana iztočnica, za katero stoji pomen. Žal pa slovar ne daje prevodnih ustreznic (primer 20), ponuja pa področne kvalifikatorje, vendar ti niso uporabljeni dosledno. 
Primer 20

CST Československá Televize

CT Critical Theory (Ss)

CTA Chicago Transit Authority

CTA Comité des travailleurs Algériens $(\mathrm{F})$

Vir: The Dictionary of Acronyms and Abbreviations in Applied Linguistics and Language Learning (Jung 1991: 100)

\subsubsection{Elsevier's Dictionary of Acronyms, Initialisms, Abbreviations and Symbols}

Izpostavila bi še Elsevier's Dictionary of Acronyms, Initialisms, Abbreviations and Symbols (Mattia 1997), ki ima podobno mikrostrukturo kot prejšnji (Jung 1991), obsežen geslovnik in vsak pomen v samostojnem geselskem članku. Geslo uvaja krepko zapisana iztočnica, za katero stoji pomen. Žal slovar ne ponuja prevodnih ustreznic in področnih kvalifikatorjev, v dodatku pa so krajšave zbrane po področjih.

2.2 V angleškem prostoru je krajšavnih slovarjev kar veliko, a le redki izhajajo pogosto. Pravo izjemo predstavlja obsežni slovar založbe Gale, ki izhaja vsako leto in dosega vrtoglave cene. Slovarji se po številu gesel zelo razlikujejo, zelo pa preseneča dejstvo, da od kar desetih obravnavanih trije nimajo prevodnih ustreznic tujih krajšav, kar seveda najverjetneje pogreša marsikateri uporabnik, saj na tak način slovar ne reši vprašanja, ampak povzroči novo. Krajšavni slovarji angleškega jezikovnega prostora se močno razlikujejo v mikrostrukuri. Velikokrat manjkajo kvalifikatorji ali pa so ti uporabljeni nedosledno; podobno je z jezikovnimi in enciklopedičnimi podatki. Nekateri imajo preobsežne dodatke, ki od uporabnika zahtevajo ponovni vpogled $\mathrm{v}$ kazalo ob vsakem iskanju niza. Zelo pozitiven pristop pa nedvomno predstavljajo obrnjeni geslovniki, ki uporabnika napotijo od razvezave do krajšave, a slovaropisci vse prepogosto pozabijo na uporabnost takega seznama, ki je po mojem mnenju nujen v vsakem krajšavnem slovarju. Izdelava takega seznama ni zahtevna. Pri angleških krajšavnih slovarjih pogrešam doslednost $\mathrm{v}$ mikrostrukturi, $\mathrm{v}$ rabi kazalk, jezikovnih podatkih, kvalifikatorjih in prevodih. Seveda pa velja opozoriti tudi na dejstvo, da se nove krajšave tvorijo vsak dan, slovarji pa izhajajo preredko, da bi jim sledili in tisti izdani hitro zastarajo.

2.3 Krajšave v nemških, italijanskih, španskih in francoskih slovarjih krajšav Pregledala sem tele slovarje iz nemškega, italijanskega, španskega in francoskega prostora: Das Wörterbuch der Abkürzungen (Steinhauer 2005), Großes Abkürzungsbuch (Koblischke 1983), Dizionario di Sigle Abbreviazioni e Simboli (Righini 2001), Dizionario delle Sigle e degli Acronimi (Malossini 1999), Dictionnaire des Abreviations et Acronymes (Murith - Bocabeille 1992) in Diccionario General de Abreviaturas Españolas (Galende 1997, 2001). 
Preglednica 2

\begin{tabular}{|l|l|l|l|l|l|l|l|}
\hline Slovar & $\begin{array}{l}\text { Število } \\
\text { gesel }\end{array}$ & $\begin{array}{l}\text { Doda- } \\
\text { tek }\end{array}$ & $\begin{array}{l}\text { Tuje } \\
\text { krajša- } \\
\text { ve }\end{array}$ & Prevod & $\begin{array}{l}\text { Kvali- } \\
\text { fikator }\end{array}$ & Jezik & $\begin{array}{l}\text { Enciklopedični } \\
\text { podatki }\end{array}$ \\
\hline Steinhauer 2005 & 50.000 & $\checkmark$ O & $\checkmark$ & $x$ & $\checkmark$ & $\checkmark x$ & $x$ \\
\hline Koblischke 1983 & 50.000 & $\checkmark$ O & $\checkmark$ & $\checkmark$ & $\checkmark$ & $\checkmark$ & $\checkmark$ \\
\hline Zingarelli 2001 & 10.000 & $x$ & $\checkmark$ & $\checkmark$ & $\checkmark$ & $\checkmark$ & $\checkmark$ \\
\hline Malossini 1999 & 8.000 & $x$ & $\checkmark$ & $x$ & $\checkmark x$ & $x$ & $x$ \\
\hline $\begin{array}{l}\text { Murith - Bocabe- } \\
\text { ille 1992 }\end{array}$ & 20.000 & $x$ & $\checkmark$ & $x$ & $x$ & $x$ & $x$ \\
\hline $\begin{array}{l}\text { Galende 1997, } \\
\text { 2001 }\end{array}$ & 20.000 & $x$ & $x$ & $x$ & $x$ & $x$ & $x$ \\
\hline
\end{tabular}

Legenda

\begin{tabular}{|l|l|l|l|l|l|l|}
\hline$x-$ ne & $\checkmark-$ da & $\begin{array}{l}\checkmark \checkmark-\text { da } \\
(\text { dosledno })\end{array}$ & $\begin{array}{l}\checkmark x-\text { da } \\
(\text { ne dosledno) }\end{array}$ & $\begin{array}{l}\checkmark \mathrm{O}-\text { da } \\
(\text { obsežni })\end{array}$ & $\begin{array}{l}\checkmark \mathrm{R}-\text { da } \\
(\text { redko) }\end{array}$ & $\begin{array}{l}\checkmark \text { PO }- \text { da } \\
(\text { preobsežno) }\end{array}$ \\
\hline
\end{tabular}

Še več razlik je v zgoraj omenjenih krajšavnih slovarjih v primerjavi z angleškimi na makro- in mikrostrukturni ravni. Razhajanja so vidna predvsem pri prevodih in kaže, da je najstarejši še najboljši, le da ni dovolj ažuren.

\subsubsection{Nemški krajšavni slovarji}

\section{(1) Das Wörterbuch der Abkürzungen}

Najnovejša slovarska pridobitev na področju krajšav v nemškem jezikovnem prostoru je Das Wörterbuch der Abkürzungen (Steinhauer 2005), ki šteje kar 50.000 krajšav, kar je seveda res veliko, žal pa slovar tujih krajšav ne prevaja oz. jih ima prevedenih le nekaj. Prevode ali razlage tujih krajšav pa pogreša marsikateri uporabnik. Avtorica pravi, da so vključene krajšave splošnega interesa. Navaja še, da so krajšave za imena podjetij in organizacij dobro znane po vsej državi, tudi na mednarodni ravni. Krajšave je zbirala s pomočjo slovarjev, enciklopedij, leksikonov, spleta idr., poleg tega pa je sodelovala s številnimi terminologi. Dodaja še, da tuje krajšave niso prevedene zato, ker naj bi bil namen slovarja predvsem podati razvezavo. Za krajšavo FIAT pa pravi, da je v nemškem prostoru znana, zanimivo pa je predvsem dejstvo, da se bralci zavedajo, da sploh gre za krajšavo. Po mnenju avtorice nemški pomen ni pomemben (A. Steinhauer v zasebni korespondenci: 2007). S to trditvijo se ne strinjam, saj bi opisni prevod ali razlaga uporabniku nedvomno koristila. Gesla v slovarju so abecedno urejena, iztočnice so zapisane modro, kar olajša iskanje in je v sodobnem slovaropisju zelo modno. Pomeni istega besednega korena so zapisani $\mathrm{v}$ enem geselskem članku in so med seboj ločeni s podpičjem, kar je razvidno iz primera 21 . 
Primer 21

jur. - juridisch; juristisch

Vir: Das Wörterbuch der Abkürzungen (Steinhauer 2005: 235)

Razvezave, ki imajo popolnoma drugačen besedni koren, pa so ločene s sredinsko piko, kar je razvidno iz primera 22.

Primer 22

Jr. - Jahr · Januar · Junior

Vir: Das Wörterbuch der Abkürzungen (Steinhauer 2005: 234)

Če obstajata dva zapisa krajšave, se drugi zapis ne pojavi kot samostojno geslo. V slovarju opazimo tudi področne kvalifikatorje in nekaj nedoslednosti pri izražanju podatkov o jeziku. Pri nekaterih tujih krajšavah podatki so, pri drugih pa ne (primera 23 in 24). Tudi prevode je mogoče najti le ponekod (primera 23 in 24). Enciklopedičnosti ni. Znotraj geslovnika lahko opazimo urejene dele, ki imajo zbrane krajšave določenih področij, npr. domene. Slovar vsebuje tudi obsežen dodatek, v katerem je seznam od krajšavnih razvezav do krajšav oz. obratni slovar, kar je za uporabnika zelo priročno.

Primer 23

f.i. - for instance (engl.: »zum Beispiel«) · free in (engl.: »frei eingeladen «)

Vir: Das Wörterbuch der Abkürzungen (Steinhauer 2005: 158)

Primer 24

FIAT - Fabbrica Italiana Automobili Torino

Vir: Das Wörterbuch der Abkürzungen (Steinhauer 2005, 158)

\section{(2) Großes Abkürzungsbuch}

Preverila sem še stanje v mnogo starejšem slovarju Großes Abkürzungsbuch (Koblischke 1983). Gesla v slovarju so abecedno urejena, iztočnice so zapisane krepko, kar olajša iskanje. Vsak pomen stoji v svojem geselskem članku, kvalifikatorji in jezikovni podatki so uporabljeni dosledno in vsako tuje geslo je prevedeno (primer 25). Na koncu slovarja stoji še zelo obsežen dodatek.

Primer 25

AAA $<$ engl $>$ American Automobile Association $=$ Amerikanischer Automobilverband (USA)

Vir: Großes Abkürzungsbuch (Koblischke 1983: 15)

Preseneča tudi, da je starejši nemški slovar veliko bolj dosleden od novejšega v smislu mikrostrukture, predvsem glede doslednosti prevodov, enciklopedičnih podatkov, kvalifikatorjev in jezikovnih podatkov, čeprav v njem seveda manjkajo najnovejše krajšave. 
- 2.3.2 Italijanski krajšavni slovarji

(1) Dizionario di Sigle Abbreviazioni e Simboli

V italijanskem prostoru imamo dva krajšavna slovarja. Dizionario di Sigle Abbreviazioni e Simboli (Righini 2001) šteje več kot 10.000 abecedno urejenih italijanskih in tujih krajšav. Vse tuje krajšave so dosledno prevedene v italijanski jezik. Dodatka k slovarju ni. Geslo je preprosto, iztočnica je zapisana krepko, pomeni so med seboj ločeni s krepkimi, ležečimi arabskimi številkami, kar je razvidno iz primera 26.

Primer 26

A. 1 (posta) Assicurata. 2 (teatro) Atto. 3 Autore.

Vir: Dizionario di Sigle Abbreviazioni e Simboli (Righini 2001: 1)

Opazimo tudi rabo področnih kvalifikatorjev in podatek o jeziku, slednji je razviden iz primera 27. Podatek o jeziku je zapisan okrajšano in ležeče, prevod stoji za tujejezično razvezavo v oklepaju.

Primer 27

ad lib. lat. ad libitum (a volontà).

Vir: Dizionario di Sigle Abbreviazioni e Simboli (Righini 2001: 6)

Tu so tudi enciklopedični podatki, zapisani ležeče, ki jih ceni vsak uporabnik (primer 28).

\section{Primer 28}

bps (elab.) ingl. bits per second (bit per secondo, unità di misura della velocità

di trasmissione dati).

Vir: Dizionario di Sigle Abbreviazioni e Simboli (Righini 2001: 41)

\section{(2) Dizionario delle Sigle e degli Acronimi}

Drugi italijanski slovar pa je Dizionario delle Sigle e degli Acronimi (Malossini 1999), ki šteje več kot 8000 abecedno urejenih, italijanskih in tujih krajšav. Tuje krajšave žal niso prevedene in tudi dodatka v slovarju ni. Geslo je preprosto, iztočnica je zapisana krepko, pomeni pa so med seboj ločeni s pikami (primer 29). Podatka o jeziku in enciklopedičnih podatkov v slovarju ni, opazimo pa lahko nekaj področnih kvalifikatorjev.

Primer 29

DRV Device Driver · Driver

Vir: Dizionario delle Sigle e degli Acronimi (Malossini 1999: 106)

\subsubsection{Francoski in španski krajšavni slovarji}

\section{(1) Dictionnaire des Abréviations et Acronymes}

Francoski Dictionnaire des Abréviations et Acronymes (Murith - Bocabeille 1992) ima preprost geselski članek, iztočnica je zapisana krepko, pomeni so med seboj ločeni tako, da stojijo vsak v svoji vrstici, pred njimi pa je pomišljaj. Posamezni po- 
meni krajšav so zbrani v enem samem geslu. Slovar vključuje angleške in francoske krajšave, kar učinkuje precej zmedeno. Krajšave žal niso prevedene (primer 30).

Primer 30

AAD

- active acoustic device

- allocation aux adultes handicapés

Vir: Dictionnaire des Abreviations et Acronymes (Murith - Bocabeille 1992: 3)

\section{(2) Diccionario General de Abreviaturas Españolas}

Španski krajšavni slovar Diccionario General de Abreviaturas Españolas (Galende 1997, 2001) zajema samo španske krajšave, tujih krajšav ni. Geslo je preprosto: iztočnica je zapisana krepko, posamezni pomeni krajšav pa so zbrani v enem samem geslu.

2.4 Geselski članki slovarjev krajšav so si v nekaterih segmentih zelo podobni, npr. iztočnice so navadno zapisane krepko, pomeni so ločeni največkrat s podpičjem, pojavljajo pa se tudi druge oblike ločevanja, npr. arabske številke pri slovarju Dizionario di Sigle Abbreviazioni e Simboli (Righini 2001). Vendar pa je tudi veliko razhajanj. Slovarji v geslovnike vključujejo domače, nekateri tudi tuje krajšave, tujih pa žal ne prevajajo vsi, nekateri jih nedosledno. Prevodi so na primer v slovarju Dizionario di Sigle Abbreviazioni e Simboli (Righini 2001) in v nekaterih angleških slovarjih. Nemški Das Wörterbuch der Abkürzungen (Steinhauer 2005) in italijanski Dizionario delle Sigle e degli Acronimi (Malossini 1999) ter tudi nekateri angleški, npr. World Guide to Abbreviations of Organizations (Buttress 1976), pa krajšav ne prevajajo ali jih nedosledno in tako uporabniku ponujajo le tujejezične krajšavne razvezave. Prevodi in razlage tujih krajšav, ki so v krajšavnih slovarjih, nedvomno koristijo uporabniku in rešijo zapleteni pomen oz. prevod krajšave. V nekaterih slovarjih opazim tudi precej dodatkov, ki so lahko zelo uporabni, če le niso preobsežni in ne zmedejo uporabnika, npr. Dictionary of Abbreviations and Acronyms (Dale 1999). Zamudno je lahko iskanje krajšave iz področno urejenega dodatka, če uporabnik ni prepričan, na katero področje sodi krajšava. V slovarjih so načeloma prisotni področni kvalifikatorji in podatki o jeziku. Nekateri vsebujejo tudi enciklopedične podatke, ki uporabniku pomagajo razumeti krajšavo v celoti. V krajšavnih slovarjih pa nikakor ni pričakovati podatka o naglasu in izgovarjavi ter primerov ali besednih zvez, v katerih se krajšava uporablja. Opaziti je mogoče veliko nedoslednosti v mikrostrukturi, najbolj moteči so nedosledni prevodi ter raba kvalifikatorjev in enciklopedičnih podatkov. Vsi obravnavani slovarji pa imajo še nekaj skupnega: vsi so že stari. Tako tudi ne moremo v njih iskati novih ali manj novih krajšav, recimo $S A R S$, ki je bil pred leti zelo aktualen, ali priljubljenih krajšav, uporabljenih predvsem med mladimi v spletnih klepetalnicah in/ali pri pisanju elektronskih tekstovnih sporočil, kot sta $B R B$ ali $L O L$. Krajšavni slovarji naj bi bili takrat, ko jih uporabljamo, čim novejši, a žal krajšave nastajajo hitreje kot novi krajšavni slovarji, in ker izdaja kakovostnega krajšavnega slovarja v pisni obliki zahteva določen čas izdelave in tudi denar ter številne strokovnjake, veliko priprav in dela, večkrat pretečejo leta, preden nov krajšavni slovar zagleda luč sveta. 


\section{- 3 Krajšavni slovarji za slovenščino}

Krajšavnih slovarjev je $\mathrm{v}$ tujih jezikih zelo veliko in nekateri jeziki jih imajo celo več vrst, v slovenščini pa niti tovrstnega sodobnega slovarja žal še kar nimamo, z izjemo spletnega Slovarčka krajšav (Kompara 2006; http://bos.zrc-sazu.si/kratice. html), ki vsebuje 5700 slovenskih in tujih krajšav. Slovenci smo sicer dobili prvi slovenski slovar krajšav Kratice: mala izdaja leta 1948 (Župančič 1948), do danes pa ni nihče napisal prenovljene izdaje ali novega tovrstnega dela. Župančičev slovar je razmeroma neznan, dostop do njega pa je omejen. Slovar, ki uporablja kot krovni pojem poimenovanja kratico, je izšel pri Državni založbi Slovenije. V slovarju niso samo krajšave iz časa nastanka slovarja in slovenskega izrazja, temveč tudi starejše in tuje krajšave, ki se zapisujejo tako, kakor so se pojavile v knjigah, revijah in časopisih. Abecedno urejeni slovarski del zajema na 36 straneh številne krajšave, ki jih danes ne uporabljamo več oziroma niso več tako pogoste, saj so vezane na obdobje nastanka slovarja oziroma na čas pred njegovim nastankom. Nekatere krajšave, predvsem tuje, imajo poleg pomena tudi razlago. Slovarju sledijo Dodatek, v katerem so krajšave za učne predmete razvrščene v posebna poglavja, indijski desetiški sestav, arabske (indijske) številke, rimske številke, računski znaki, dolžinske mere, ploskovne mere, prostorninske mere, utežne mere, časovne mere, kratice za denar in celo preračunski tečaj z nekaterimi valutami, oznake za formate papirja, znaki za strani neba in nekateri kemični elementi (Župančič 1948: 3-61). Leta 1947 so bile pod naslovom Kratice objavljene krajšave v svojem Koledarju Mohorjeve družbe. Leta 1971 pa je izšel Rečnikjugoslovenskih skraćenica avtorja Josipa Zidarja (Zidar 1971). Kljub temu da je bil Župančičev slovar izdelan mnogo pred računalniško dobo, ob okrnjenih sredstvih, pripomočkih in verjetno tudi nabora strokovnjakov ter povezavo s tujimi viri in strokovnjaki, lahko trdim, da je napisan dobro in odraža svoj funkcionalni namen. Težava je $\mathrm{v}$ tem, da je danes krajšav veliko več kot takrat, ko je izšel.

\subsection{Kje še zasledimo krajšave}

3.1.1 V dodatku Slovarčka tujk in kratic (Verbinc 1969) je na sedmih straneh zajetih približno 300 pogostejših domačin in tujih krajšav ter razvezav. Vse tuje krajšave in razvezave so tudi prevedene. Lahko trdim, da je geselski članke popoln in uporabniku prijazen, saj poleg razvezave in prevoda, ponuja tudi jezikovne kvalifikatorje in kjer je to potrebno tudi enciklopedične podatke.

3.1.2 V slovenskem prostoru lahko krajšave najdemo v Velikem slovarju tujk iz leta 2002, ki je krajšavam namenil posebno dodatno poglavje z naslovom Simboli, kratice in okrajšave, ki šteje 12 strani (VST: 1289-1300). Na koncu Velikega slovarja tujk je še poglavje, v katerem so zajete krajšave, uporabljene v slovarju (VST: 1301-1303). Ker število krajšav hitro narašča, saj nenadoma pridejo $\mathrm{v}$ jezik in $\mathrm{v}$ nekaterih primerih tudi nenadoma izginejo iz njega, so tudi težko ulovljive. Splošni slovarji v knjižni obliki jim po eni strani navadno ne namenjajo dovolj prostora in pozornosti, po drugi strani pa krajšavni slovarji preprosto preredko izhajajo, da bi bili kos spremembam. Na voljo so še drugi načini beleženja krajšav; izpostaviti je 
treba predvsem spletne zbirke, ki so lahko veliko bolj ažurne. Nekatere med njimi uporabniku omogočajo celo, da sam dodaja krajšave in krajšavne razvezave.

3.1.3 Primer spletne zbirke je Slovarček krajšav (Kompara 2006). Med tujimi gesli v njem so francoske, italijanske, nemške, angleške, španske in ruske krajšave, ki se uporabljajo v slovenskem prostoru. Krajšave so razvezane, tuje pa imajo tudi slovenski prevod. Nekatere krajšave imajo več različnih pomenov, ki so navedeni v enem slovarskem geslu (npr. $C D$ ) in ločeni z arabskimi številkami. Tuje krajšave imajo pred pomenom označen izvorni jezik. Slovarček krajšav sicer ni razlagalni, ampak ponekod vseeno vsebuje razlage krajšav, tujih in slovenskih (npr. MAT in $C E$ ), kot dodatno pomoč pri zapletenem iskanju ustreznega pomena krajšave. Slovarček krajšav je nastajal od leta 2004 in je od svoje spletne postavitve postal bogatejši za več kot tisoč krajšav. Žal pa se delo v zadnjem času ažurira vse redkeje. Krajšave v Slovarčku krajšav so preverjene v različnih virih (http://bos.zrc-sazu.si/ kratice.html - seznam virov). Prednost spletne zbirke sta možnost hitrega ažuriranja in preprosto iskanje. Slovarček krajšav ima sicer najobsežnejši geslovnik v slovenskem prostoru, a v primerjavi z drugimi jeziki še vedno zaostaja. Delo bi bilo smiselno izboljšati in ustrezno dograditi ter dodati del, ki bralca popelje od razvezave do krajšave.

3.1.4 Podobna spletna zbirka, ki poleg področne terminologije zajema tudi krajšave, je Evroterm (http://www.sigov.si/evroterm/), terminološka zbirka izrazov, ki je začela nastajati med pripravljanjem slovenske različice pravnih aktov Evropske unije v okviru Sektorja za prevajanje, redakcijo in terminologijo Službe Vlade RS za evropske zadeve (SVEZ). Na spletu je na voljo od avgusta 2000, ureja in dopolnjuje se dnevno, vsebuje pa okrog 88.678 izrazov, ki izvirajo iz prevodov pravnih aktov EU in drugih dokumentov, ki jih prevajajo v državni upravi. Zbirka je večjezična in zajema številne jezike, žal pa vsi jeziki niso tako dobro zastopani kot angleščina. V zbirki so tudi krajšave, predvsem kratice angleškega izvora, ki so vedno prevedene $\mathrm{v}$ slovenski jezik in občasno tudi v druge tuje jezike, ni pa okrajšav in slovenskih krajšav. Zbirka vsebuje okrog 4000 krajšav, a je žal zastopanost krajšav $\mathrm{v}$ primerjavi z drugimi termini še vedno precej skromna in krajšavam je v zbirki namenjen le drugotni pomen. Zato bi bilo za slovenski prostor smiselno zgraditi krajšavni slovar, ki je uporabniku lahko na voljo v knjižni obliki ali na spletu. Mora pa biti ažuren in predvsem dovolj obsežen. Seveda pa na spletu kar mrgoli tujih, predvsem angleških krajšavnih zbirk oziroma iskalnikov krajšav.

3.1.5 Omeniti velja še zbirko IATE (Inter-Active Terminology for Europe; http:// iate.europa.eu/iatediff/SearchByQuery.do); gre za medinstitucionalno terminološko zbirko Evropske unije, ki jo od leta 2004 uporabljajo inštitucije in agencije Evropske unije. Projekt se je začel izvajati leta 1999 zato, da bi zgradili spletno zbirko $E U$ terminologije in standardizirali informacije. Zbirka združuje vse obstoječe zbirke prevajalskih oddelkov $E U \mathrm{v}$ eno samo interaktivno in prosto dostopno zbirko, ki pa je žal nepopolna in nekonsistentno grajena, saj v njej npr. krajšava NATO ni prevedena v slovenščino, v druge jezike pa je. Poleg tega je treba od vpisu krajšave izbrati 
- $\quad$ izvorni jezik, kar učinkuje precej zamudno. Velikokrat pa tudi ne vemo izvornega jezika krajšave, saj se v marsikaterem jeziku namesto prevedene različice uporablja izvirna. Zelo moteče je tudi navajanje razvezav in prevodov vsake ustanove posebej v svoji preglednici. Uporabnik naj bi tako bil prepuščen lastni presoji in sam izbral ustreznico. Tovrstni pristop utegne na uporabnika učinkovati zelo neresno. Težavo bi lahko preprosto rešili z znotrajinstitucionalnim poenotenjem in podporo informatikov.

3.2 Med večjimi zbirkami gre omeniti še nekaj tujih, kot je Acronym Finder (http://www.acronymfinder.com/), ki uporabniku omogoča iskanje krajšav ali krajšavnih razvezav in tudi vnos nove razlage krajšave. Podobno deluje tudi The Free Dictionary (http://acronyms.thefreedictionary.com/). Spletne zbirke so nedvomno ažurnejše od knjižnih, se pa nove krajšave $\mathrm{v}$ jezikih pojavljajo izredno hitro, prehitro, da bi jih ročno oz. nesamodejno beležili v obsežne zbirke. Ročno beleženje krajšav v geslovnike spletnih zbirk je zamudno, nenatančno in prepočasno. Zato se številni raziskovalci vse pogosteje ukvarjajo s problematiko samodejnega prepoznavanja krajšav v besedilih in samodejnega oblikovanja spletnih slovarjev in zbirk krajšav (o tem Kompara 2009).

\section{$4 \quad$ Prihodnost}

Izgradnja krajšavnega slovarja $\mathrm{v}$ slovenskem prostoru je ključnega pomena. Največ krajšavnih slovarjev je mogoče najti v angleškem prostoru. Tovrstni slovarji so prisotni tudi pri Italijanih, Špancih, Nemcih in Francozih. V slovenskem prostoru pa z izjemo spletnega Slovarčka krajšav še nimamo pravega in obsežnega dela, namenjenega krajšavam. Krajšave seveda lahko najdemo tudi $\mathrm{v}$ nekaterih drugih delih, pravopisih, Velikem slovarju tujk in Evrotermu, a žal le v naboru do največ 4000 gesel, kar je občutno premalo. Smiselno bi bilo nadgraditi že obstoječi spletni Slovarček krajšav in izkoristiti spletne prednosti, med drugim tudi hitro ažuriranje in preprosto iskanje. Slovar bi bilo treba povečati za vsaj še 5000 gesel in ga tako narediti primerljivega tujim. Seveda pa to predstavlja celostni projekt, h kateremu bi bilo smiselno povabiti tudi strokovnjake za posamezna področja.

\section{$5 \quad$ Sklep}

Krajšave so postale del našega vsakdana in so močno prisotne $v$ našem življenju in v vsakem jeziku. Nastajajo tako rekoč dnevno, nekatere ostanejo v jeziku za vedno, druge čez čas počasi izginjajo iz rabe in nanje preprosto pozabimo. Tuji jeziki imajo številne krajšavne slovarje, Slovenci pa smo bili deležni prvega slovarja krajšav leta 1948. Nastal je brez ustrezne računalniške podpore in spleta, a kljub temu popolnoma ustreza funkcionalnemu namenu. Žal pa prav zaradi hitrega nastajanja novih krajšav krajšavni slovarji hitro zastarajo in so pomanjkljivi. Na spletu krajšavnih 
slovarjev kar mrgoli, prednost spletnega slovarja pa je nedvomno v preprostem iskanju in hitrem ažuriranju. Poleg tega so spletni slovarji običajno prosto dostopni. $\mathrm{V}$ prispevku na podlagi pregleda zastopanosti krajšav v slovarjih in pregleda tujih krajšavnih slovarjev sem želela opozoriti na to, da je izgradnja slovenskega slovarja krajšav temeljnega pomena za slovensko družbo.

\section{Viri in literatura}

Geddes - Grosset 1999 = Abbreviations and Acronyms, New Lanark: Geddes Grosset, 1999.

Acronym Finder [http://www.acronymfinder.com/].

Barnhart 1995 = K. R. Barnhart, The Barnhart Abbreviations Dictionary, 1995 [http://eu.wiley.com/WileyCDA/WileyTitle/productCd-0471571466.html].

Buttress $1976=$ F. A. Buttress, World Guide to Abbreviations of Organizations, London: L. Hill - Detroit: Gale Research Co., 1976.

Dale $1999=$ R. Dale - P. S. Dale, Dictionary of Abbreviations and Acronyms, Hertfordshire: Wordsworth, 1999.

Debenjak 2003 = D. Debenjak - B. Debenjak - P. Debenjak, Veliki slovenskonemški slovar, Ljubljana: DZS, 2003.

De Sola 1986 = R. De Sola, Abbreviations Dictionary, New York idr.: Elsevier, ${ }^{7} 1986$.

DUW = G. Drosdowski (ur.), Deutsches Universalwörterbuch, Mannheim idr.: Duden Verlag, 1989.

Evroterm: večjezična terminološka zbirka [http://evroterm.gov.si/index.php?jezik= slov].

Faudouas $1990=$ J. C. Faudouas, Dictionnaire des Abréviations Courantes de la Langue Française, Paris: La Maison du Dictionnaire, 1990.

Fergusson $2000=$ R. Fergusson, The New Penguin Dictionary of Abbreviations: from A to ZZ, London: Penguin, 2000.

Gabrovšek 1994 = D. Gabrovšek, Kodifikacija angleškega jezika v specializiranih enojezičnih slovarjih: Too much of everything?, Vestnik: Društvo za tuje jezike in književnosti 28 (1994), št. 1-2, 150-180.

Gabrovšek idr. 2005-2006 = D. Gabrovšek idr., Veliki angleško-slovenski slovar Oxford-DZS, Ljubljana: DZS, 2005-2006.

Gale Research Company 2006 = Acronyms, Initialisms and Abbreviations Dictionary [http://www.gale.cengage.com/pdf/samples/sp628573.pdf].

Gale Research Company 2007 = Reverse Acronyms Initialisms \& Abbreviations Dictionary [http://www.gale.cengage.com/servlet/ItemDetailServlet?region $=9 \&$ imprint $=000 \&$ titleCode $=$ RAIAD\& $\mathrm{cf}=\mathrm{p} \&$ type $=3 \& \mathrm{id}=241088]$.

Galende 1997, 2001 = J. C. Galende, Diccionario General de Abreviaturas Españolas, Madrid: Editorial Verbum, 1997, 2001.

García Marquez 2002 = G. García Marquez, Clave: Diccionario de Uso del Español, Madrid: Ediciones Sm. 
IATE, 2002 [http://iate.europa.eu/iatediff/SearchByQueryLoad.do;jsessionid=9ea7 991c30d57ad56f9aea524f88ae39a587b5b18a1e.e3iLbNeKc3mSe3aNbxuQ a3iPci0?method=load].

Jung 1991 = H. Jung - Udo O. H. Jung, The Dictionary of Acronyms and Abbreviations in Applied Linguistics and Language Learning, Frankfurt am Main itd.: Peter Lang Publishing Group, 1991.

Koblischke 1983 = H. Koblischke, Großes Abkürzungsbuch, Leipzig: VEB Bibliographisches Institut, 1983.

Kompara 2005 = M. Kompara, Slovensko-italijanski glosar krajšav: diplomsko delo, Ljubljana, 2005.

Kompara $2006=$ Slovarček krajšav [http://bos.zrc-sazu.si/kratice.html].

Kompara 2009 = M. Kompara, Prepoznavanje krajšav v slovenskih elektronskih besedilih, Jezikoslovni zapiski 15 (2009), št. 1-2, 95-112.

Kratice $=$ Kratice, Koledar Mohorjeve družbe: za prestopno leto 1948, Celje: Mohorjeva družba, 1947, 39-40.

Malossini 1999 = A. Malossini, Dizionario delle sigle e degli acronimi, Milano: Avallardi, 1999.

Murith - Bocabeille 1992 = J. Murith - J. M. Bocabeille, Dictionnaire des Abreviations et Acronymes, Paris: TEC\&DOC - Lavoisier, 1992.

Mattia $1997=$ F. B. Mattia, Elsevier's Dictionary of Acronyms, Initialisms, Abbreviations and Symbols, Amsterdam: Elsevier Science B.V.,1997.

Paxton 1983 = J. Paxton, Everyman's Dictionary of Abbreviations, London: J. M. Dent \& Sons, 1983.

Righini 2001 = E. Righini, Dizionario di sigle abbreviazioni e simboli, Bologna: Zanichelli.

Robert 1996 = P. Robert, Le nouveau Petit Robert, Paris: Dictionnaires Le Robert, 1996.

Sinclair 1999 = J. Sinclair, Collins COBUILD English Dictionary, London: HarperCollins, 1999.

Steinhauer 2005 = A. Steinhauer, Das Wörterbuch der Abkürzungen, Mannheim idr.: Duden Verlag, 2005.

Šlenc 2006 = S. Šlenc, Veliki slovensko-italijanski slovar, Ljubljana: DZS, 2006.

The Free Dictionary [http://acronyms.thefreedictionary.com/].

Verbinc 1969 = F. Verbinc, Slovarček tujk in kratic, Ljubljana: Prešernova družba, 1969.

VST = M. Tavzes idr., Veliki slovar tujk, Ljubljana: Cankarjeva založba, 2002.

Zidar 1971 = J. Zidar, Rečnikjugoslovenskih skraćenica, prev. I. Fesenko, Beograd: Međunarodna politika, 1971.

Zingarelli $2000=$ N. Zingarelli, Vocabolario della lingua italiana, Bologna: Zanichelli, 2000.

Župančič 1948 = J. Župančič, Kratice: mala izdaja, Ljubljana: DZS, 1948. 


\section{Dictionaries of abbreviations}

\section{Summary}

Abbreviations have become part of everyday experience and have a strong presence in life and in every written language. New ones are being formed every day; some become a permanent part of the language, whereas others gradually fall out of use and are simply forgotten. Dictionaries of abbreviations exist in many languages, and the first Slovenian one appeared in 1948. Although this dictionary was created without modern software and internet access, it nonetheless completely fulfills its function. Unfortunately, however, dictionaries of abbreviations quickly become outdated and insufficient due to the rapid creation of new abbreviations. Dictionaries of abbreviations abound on the internet; online dictionaries have the clear advantage of simple searching and rapid updating. In addition, online dictionaries are usually easy to access. This article examines the presence of abbreviations in dictionaries and provides an overview of non-Slovenian dictionaries of abbreviations, thereby drawing attention to the fact that creating a Slovenian dictionary of abbreviations is of fundamental significance to Slovenian society. 